\title{
Terapêutica no carcinoma de células escamosas cutâneo em gatos
}

\author{
Therapeutic of cutaneous squamous cell carcinoma in cats
}

\author{
Isabelle Ferreira $^{1}$ Sheila Canevese Rahal ${ }^{2}$ Juliana Ferreira ${ }^{3}$ Thaís Pagni Corrêa ${ }^{4}$
}

\section{RESUMO}

O carcinoma de células escamosas é uma neoplasia cutânea de grande relevância em países de clima tropical como o Brasil, uma vez que a exposição crônica à radiação ultravioleta é um dos fatores importantes para o desenvolvimento da doença. Esta revisão tem por objetivo discorrer sobre alternativas de tratamento do carcinoma de células escamosas em gatos, com ênfase à terapia fotodinâmica. A escolha da modalidade terapêutica deve ser estabelecida de acordo com o estadiamento do tumor, o estado geral do paciente, a colaboração do proprietário e a disponibilidade de equipamentos e fármacos. A precocidade no diagnóstico tem efeito fundamental no prognóstico.

Palavras-chave: carcinoma de células escamosas, oncologia, terapêutica, doença de gatos.

\section{ABSTRACT}

Squamous cell carcinoma is a cutaneous tumor with significant relevance in tropical climate countries such as Brazil, since chronic exposure to ultraviolet radiation is one of the important factors to disease development. The aim of this paper is to describe the treatment alternatives to squamous cell carcinoma in cats, with special emphasis to photodynamic therapy. The choice of treatment modalities should be determinated according to tumor staging, general state of the patient, owner's cooperation, and availability of equipment and drugs. The early diagnosis has fundamental effect on prognosis.

Key words: squamous cell carcinoma, oncology, therapeutic, cat's disease.

\section{INTRODUÇÃO}

A pele e o tecido subcutâneo são locais comuns de neoplasia primária em gatos e o carcinoma de células escamosas encontra-se entre os quatro tumores mais comuns a atingir essas regiões (ROGERS, 1994). Embora a etiologia seja desconhecida, há citações da importância de fatores relacionados ao hospedeiro e ao ambiente (THOMAS \& FOX, 2002).

Os gatos de pelagem branca são mais propensos a apresentar a doença que os pigmentados; nesses últimos, o tumor se desenvolve em áreas com pouco pelo e sem pigmento (RUSLANDER et al., 1997). Os gatos da raça Siamês e os de pelagem preta são os menos predispostos (MOORE \& OGILVIE, 2001). A exposição à irradiação ultravioleta da luz solar contribui para o desenvolvimento da neoplasia (BURROWS et al., 1994; RUSLANDER et al., 1997; STRAW, 1998). Não foi detectada uma associação da neoplasia com o vírus da leucemia felina, porém não está totalmente esclarecido se há relação desta com o vírus da imunodeficiência felina. (MOORE \& OGILVIE, 2001).

A maioria das lesões está localizada na cabeça, mais freqüentemente no plano nasal, seguida pelas aurículas e pálpebras (BURROWS et al., 1994; MOORE \& OGILVIE, 2001). O dígito pode também ser local para desenvolvimento primário da neoplasia (ROGERS, 1994). Gatos que apresentam tumores nas pálpebras geralmente têm outros localizados no plano

\footnotetext{
${ }^{1}$ Curso de Medicina Veterinária da Faculdade de Medicina Veterinária e Zootecnia (FMVZ), Universidade Estadual Paulista (Unesp), Rubião Júnior s/n, 18618000, Botucatu, SP, Brasil.

${ }^{2}$ Departamento de Cirurgia e Anestesiologia Veterinária, FMVZ, Unesp, Botucatu, SP, Brasil. Email: sheilacr@fmvz.unesp.br.

${ }^{3}$ Curso de Pós-graduação do Departamento de Patologia da Faculdade de Medicina, Universidade de São Paulo (USP), Ribeirão Preto, SP, Brasil.

${ }^{4}$ Cirurgia de Pequenos Animais da FMVZ, Unesp, Botucatu, SP, Brasil.
} 
nasal ou aurículas, o que é consistente com a indução actínica (MOORE \& OGILVIE, 2001).

$\mathrm{O}$ tumor pode ser observado em gatos jovens, mas a média de idade é 11 anos e quatro meses, segundo RUSLANDER et al. (1997). A afecção pode estar presente por meses ou anos e, em geral, a história clínica está associada à presença de ferimento que não cicatriza (MOORE \& OGILVIE, 2001). No início, as lesões são proliferativas, hiperêmicas, crostosas e posteriormente evoluem para úlceras com invasão de tecidos adjacentes (RUSLANDER et al., 1997; STRAW, 1998). O tumor é localmente agressivo e com baixa taxa de metástase para linfonodos regionais e pulmão (STRAW, 1998). Dependendo da localização e extensão, muitas vezes o animal demonstra apenas um pequeno desconforto (ROGERS, 1994). Baseado nos sinais clínicos, o diagnóstico definitivo pode ser feito por citologia aspirativa ou biopsia da massa tumoral (ROGERS, 1994; THOMAS \& FOX, 2002).

A prevenção é fator importante no carcinoma de células escamosas e proprietários de gatos susceptíveis ao processo devem ser instruídos a limitar ao máximo a exposição dos animais à luz solar, restringindo-a ao início da manhã ou final da tarde (RUSLANDER et al., 1997; MOORE \& OGILVIE, 2001). Para aqueles que apresentam o hábito de se manter em frente a janelas, estas devem receber filme protetor ultravioleta (MOORE \& OGILVIE, 2001). Bloqueadores solares podem ser aplicados nas aurículas e plano nasal para auxiliar na proteção (RUSLANDER et al., 1997).

Especialmente no Brasil, o carcinoma de células escamosas representa um problema clínicocirúrgico sério, uma vez que a exposição crônica à radiação ultravioleta é um dos fatores importantes para o desenvolvimento da doença. Assim, esta revisão tem por objetivo discorrer sobre alternativas de tratamento do carcinoma de células escamosas em gatos, com ênfase à terapia fotodinâmica.

\section{TRATAMENTO}

Existem várias modalidades de tratamento para o carcinoma de células escamosas, incluindo cirurgia, criocirurgia, radiação ionizante, quimioterapia e terapia fotodinâmica (STRAW, 1998). O diagnóstico precoce é essencial, já que lesões pequenas podem ser erradicadas (THOMAS \& FOX, 2002). O grau de diferenciação celular (THOMAS \& FOX, 2002) assim como o tamanho do tumor e a profundidade da erosão são importantes para a determinação do prognóstico (MOORE \& OGILVIE, 2001). A escolha do tratamento é dependente não somente do estadiamento do tumor, mas do grau de aceitação do proprietário com relação aos efeitos colaterais e às mudanças estéticas e da disponibilidade de equipamentos e fármacos (MOORE \& OGILVIE, 2001).

A meta do tratamento cirúrgico é a remoção de suficiente tecido para deixar margens cirúrgicas livres de células neoplásicas, ao mesmo tempo em que mantém a função e a estética (ROGERS, 1994). As lesões localizadas na aurícula devem ser excisadas com margens de 1 a $2 \mathrm{~cm}$ no mínimo, embora ainda persista chance de recidiva (RUSLANDER et al., 1997). Em geral, os gatos toleram bem o procedimento de nosectomia e se recuperam rapidamente (DONNER, 1992). No entanto, o prognóstico é menos efetivo após a excisão de lesões localizadas no nariz externo ou pré-maxila (RUSLANDER et al., 1997), fato também observado nos procedimentos efetuados pelos autores da presente revisão, devido ao alto índice de recidivas (Figura 1a).

WITHROW \& STRAW (1990) realizaram a remoção cirúrgica completa do plano nasal em oito gatos com carcinoma de células escamosas, com idade média de 13 anos. No pós-operatório foi observada a formação de crosta sobre as novas aberturas nasais, que interferiam na respiração. Posteriormente, a margem da pele e turbinados re-epitelizaram. Três animais apresentaram recidiva com um, dois e cinco meses. $\mathrm{O}$ restante permaneceu sem recorrência com um período de observação que variou de oito a 27 meses.

A criocirurgia é indicada para tumores superficiais não-invasivos com menos de $0,5 \mathrm{~cm}$ em diâmetro, ou quando a cirurgia não pode ser realizada por limitações anatômicas ou devido à não concordância do proprietário (RUSLANDER et al., 1997). Como o método não é seletivo para o tecido normal ou o neoplásico, ocorrem edema, necrose e cicatrização por segunda intenção (DONNER, 1992). Alguns autores não a recomendam como modalidade terapêutica única em felinos (THOMAS \& FOX, 2002).

CLARKE (1991) realizou estudo retrospectivo com 102 gatos com carcinoma de células escamosas que foram tratados pela criocirurgia com nitrogênio líquido. O diagnóstico foi baseado na história, pois a biopsia não foi efetuada rotineiramente e nenhum prognóstico histopatológico foi disponível. Ocorreu remissão, com um único tratamento, de todas as lesões localizadas nas aurículas e pálpebras e de $70 \%$ das nasais. Dos gatos com lesões nasais $(n=90)$, 84\% não tiveram recidiva do tumor com 12 meses e $58 \%$, após 87 meses. As complicações após o tratamento foram anorexia, obstrução temporária das narinas, espirro e epífora.

A efetividade da radioterapia para o tratamento do carcinoma de células escamosas do plano nasal é inconsistente. A profundidade da penetração e 
a dose total que pode ser aplicada de forma segura são dependentes do tipo de radiação (THOMAS \& FOX, 2002). Uma das principais desvantagens do método é a necessidade de várias anestesias gerais, já que a dose de radiação deve ser dividida em múltiplos tratamentos (DONNER, 1992). Adicionalmente, gatos positivos para o vírus da imunodeficiência felina são mais susceptíveis ao desenvolvimento de toxicidade cutânea (MOORE \& OGILVIE, 2001).

COX et al. (1991) trataram, por meio de radioterapia, 13 gatos com carcinoma de células escamosas do plano nasal. A taxa de sobrevivência foi de $61,5 \%$ no período de um ano, 23\% em dois anos e $15 \%$ em três anos. Nos casos em que havia tecido disponível para avaliação histopatológica ( $n=9$ ), o êxito de tratamento não pode ser correlacionado com a diferenciação celular, índice mitótico, quantidade de produção de ceratina, ou pleomorfismo.

THÉON et al. (1995) utilizaram a radioterapia de ortovoltagem em 90 gatos com carcinoma de células escamosas do plano nasal. Foi utilizada distância entre fonte-pele de $50 \mathrm{~cm}$ e dose de radiação de $40 \mathrm{~Gy}$, administrada em 10 frações de 4 Gy em três semanas e meia. A taxa de sobrevivência livre de progressão foi de $60,1 \%$ para um ano e de $10,3 \%$ para cinco anos. A cor do pêlo, a presença de múltiplos carcinomas faciais, o grau histológico e o vírus da imunodeficiência felina não interferiram no prognóstico.

Radiação com feixe de prótons foi aplicada, por FIDEL et al. (2001), em 15 gatos com carcinoma de células escamosas no plano nasal. A média de sobrevivência foi de 946 dias. Os efeitos colaterais foram mínimos, com $60 \%$ de resposta completa, 33\% com reposta parcial e 6,6\% sem nenhuma resposta à terapia.

A quimioterapia, conforme MOORE \& OGILVIE (2001), não é muito utilizada para o carcinoma cutâneo de células escamosas em gatos. Dois dos fármacos mais efetivos em humanos e cães não são considerados seguros em gatos; a cisplatina pode causar edema pulmonar agudo fatal e o 5-fluorouracil induz neurotoxicidade (RUSLANDER et al., 1997). A bleomicina foi empregada por via subcutânea ou intravenosa em quatro gatos com carcinoma de células escamosas, com resposta parcial transitória em três deles (BUHLES \& THEILEN, 1973). Além disso, uma combinação de doxorubicina (20 a 30 $\mathrm{mg} \mathrm{m}^{-2} \mathrm{IV}$, a cada três semanas) e bleomicina (10UI m ${ }^{-2}$ IM ou IV por quatro dias, então uma vez semanalmente) promoveu a remissão em apenas um de quatro gatos tratados (RUSLANDER et al., 1997). O mesmo foi observado pelos autores da presente revisão quando empregaram este último protocolo, com o intuito de controlar a recidiva de carcinoma após nosectomia (Figura 1b), com reaparecimento da lesão após cinco meses de tratamento (Figura 2a).

A carboplatina intratumoral, na dose de $100 \mathrm{mg} \mathrm{m}^{-2}$ por área de superfície corpórea, com ou sem óleo de gergelim purificado, foi utilizada em 18 gatos com estágios avançados de carcinoma de células escamosas localizados no plano nasal por THÉON et al. (1996). O uso do óleo de gergelim reduziu a exposição sistêmica à carboplatina e evitou a perda do

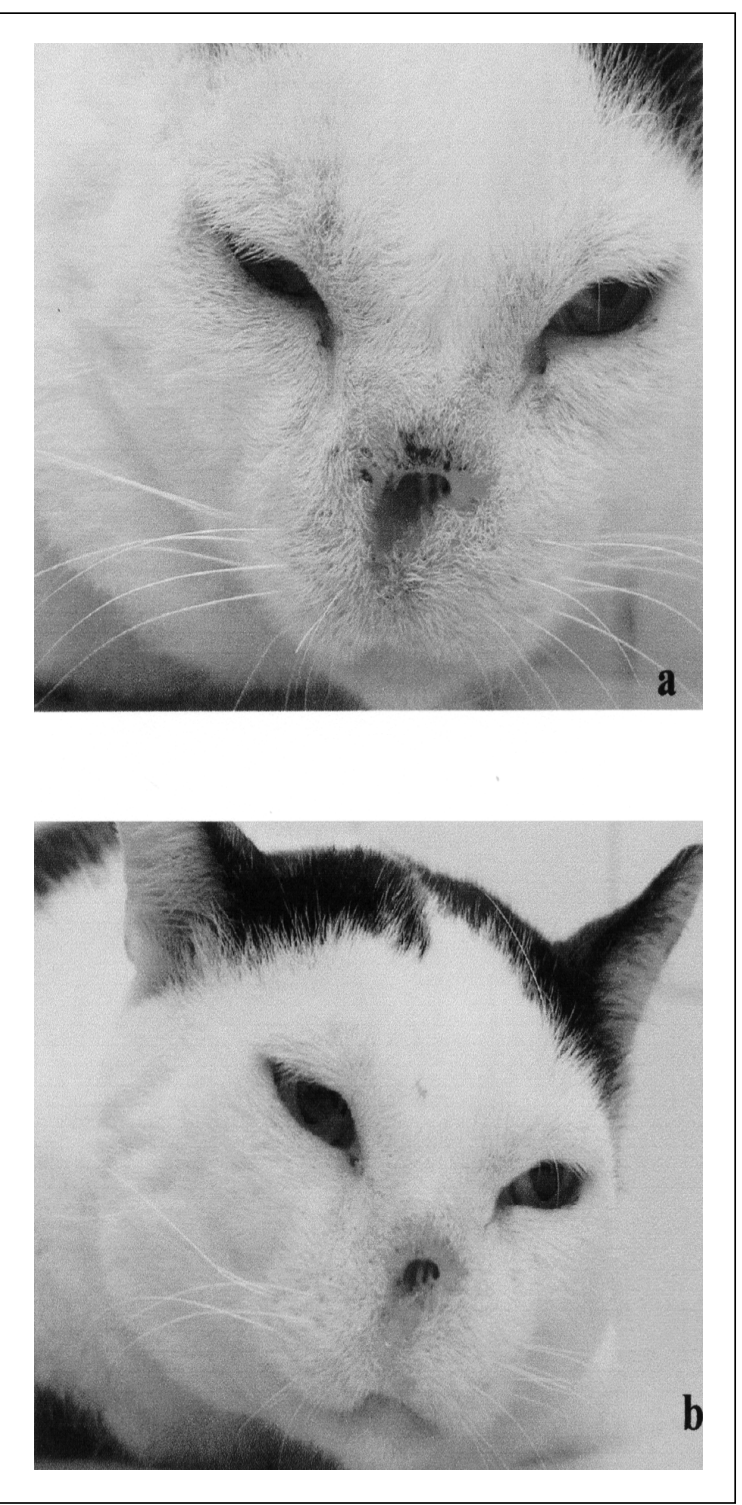

Figura 1 - Evolução de tratamentos utilizados em um gato com carcinoma de células escamosas localizado desde o dorso do nariz externo até o plano nasal. (a) Recidiva da lesão após quatro meses da nosectomia. (b) Resposta positiva após início de quimioterapia com doxorubicina e bleomicina.

Ciência Rural, v.36, n3, mai-jun, 2006. 
quimioterápico pelos locais de injeção. O uso de repetidas administrações intratumorais não promoveu efeito cumulativo nas concentrações plasmáticas ou toxicose sistêmica. Em um ano, a taxa de sobrevivência sem recidiva foi em torno de 55,1\%. Recorrência ocorreu em sete gatos.

Uma outra opção mais recente e promissora de tratamento clínico é a terapia fotodinâmica (MERKEL \& BIEL, 2001; DANIELL \& HILL, 1991; RUSLANDER et al., 1997). Esta induz a citotoxicidade das células proliferativas através de uma fonte de luz, sendo necessários um agente fotossensibilizador, luz de comprimento de onda adequado e oxigênio molecular (MERKEL \& BIEL, 2001). Durante a terapia fotodinâmica, o fotossensibilizador ligado ao tumor é ativado na presença da luz. Essa ativação leva o agente fotossensibilizador do estado fundamental ao estado excitado. As moléculas excitadas podem retornar ao estado fundamental emitindo energia na forma de fluorescência, por meio da liberação de fótons, ou progredir na cadeia de reações químicas transformandose na espécie reativa chamada triplete. As moléculas no estado triplete podem interagir diretamente com substratos biológicos e formar radicais livres, denominada de reação tipo I, ou podem transferir sua energia diretamente para o oxigênio celular e formar o oxigênio singlete altamente reativo e responsável pela morte celular, chamada de reação tipo II (DANIELL \& HILL, 1991; HENDERSON \& DOUGHERTY, 1992; MACHADO, 2000).

A maioria dos fotossensibilizadores é retida tanto nos tecidos normais como nos neoplásicos (HENDERSON \& DOUGHERTY, 1992). O agente fotossensível, segundo MACHADO (2000), tende a se concentrar no tecido lesado, mas o mecanismo não está totalmente esclarecido. Apesar desta retenção não ser muito bem compreendida, alguns fatores são descritos como responsáveis. A permeabilidade da membrana das células tumorais encontra-se alterada, as fibras colágenas que interagem no tumor são imaturas e semelhantes às observadas em tecidos embrionários e em processo de cicatrização recente. Essas fibras imaturas apresentam grande capacidade de ligação às porfirinas, constituindo um local para retenção e acúmulo do agente fotossensibilizador. Outros fatores como a rede linfática pouco desenvolvida, a presença de macrófagos e o menor $\mathrm{pH}$ intracelular também levam a uma maior concentração do fármaco nas células tumorais. Sabe-se que a necrose e a apoptose são dependentes do fotossensibilizador e das condições do tratamento (DOUGHERTY, 2002). A resposta apoptótica não depende do ciclo celular ou de fatores genéticos (DOUGHERTY et al., 1998).
MACHADO (2000) citou que a primeira geração de agentes fotossensibilizadores baseia-se em mistura de derivados porfirínicos. A segunda geração, como as ftalocianinas e as clorinas, podem ser excitadas com radiação de comprimento de ondas maiores, quando o tecido biológico absorve menos e a profundidade de penetração da luz é maior, e apresentam um período de eliminação mais curto. $\mathrm{O}$ fotossensibilizador pode ser aplicado intravenoso ou tópico (MERKEL \& BIEL, 2001).

Os fotossensibilizadores mais utilizados são os de primeira geração, tal como o Photofrin (MERKEL \& BIEL, 2001). Este foi desenvolvido em fins da década de 80 , sendo o primeiro agente fotossensibilizador a ser autorizado por órgãos governamentais (MACHADO, 2000). A medicação é ativada com um comprimento de onda de 630nm (MERKEL \& BIEL, 2001). Entre seus efeitos colaterais está a indução de prolongada fotossensibilidade dérmica e ocular (MACHADO, 2000).

Outro importante componente na terapia fotodinâmica é a fonte de luz (HENDERSON \& DOUGHERTY, 1992). As fontes de radiação são, em geral, laser; entretanto, estes possuem um custo elevado (MACHADO, 2000). A disponibilidade do laser de diodo tornou o valor das fontes de luz mais acessíveis, visto ser um quarto do valor do laser de argônio (DOUGHERTY, 1993). Quando se utilizam os derivados de hematoporfirinas, o tempo de espera para iluminação deve ser de 24 a 72 horas após a administração (MACHADO, 2000).

A terapia fotodinâmica tem vantagens como repetição sem resistência ao fármaco, pode ser usada com outras terapias e produz mínimo desfiguramento comparado à cirurgia, visto a destruição tecidual ser seletiva (MERKEL \& BIEL, 2001). Há controle local agressivo do processo maligno, sem dano extenso às estruturas normais circundantes (DANIELL \& HILL, 1991). O principal problema é a fotossensibilização. Embora o fotossensibilizador seja rapidamente removido do soro, pode haver retenção na pele por várias semanas (MERKEL \& BIEL, 2001). Desta forma, o animal deve ser mantido na ausência da luz solar no mínimo por duas semanas. Pode ocorrer também edema facial, eritema e necrose secundária no local de aplicação, mas que regride com o tempo (RUSLANDER et al., 1997). Um outro inconveniente é a necessidade de anestesia geral durante a aplicação e o emprego de bandagens ou colar elizabetano após a aplicação para evitar auto-traumatismo (LUCROY et al., 1996). As maiores causas de falha são a dosimetria inadequada de luz e/ou a ação do fotossensibilizador, fatores que estão sendo constantemente aprimorados pela 
interação de profissionais de áreas afins (DANIELL \& HILL, 1991).

No Brasil, a equipe do Grupo de Óptica do Instituto de Física da USP de São Carlos (IFSC), sob supervisão do Dr. Vanderlei Bagnato (Informe verbal), desenvolveu um dispositivo à base de LEDs vermelhos em 630 nm (diodos emissores de luz) para aplicação em terapia fotodinâmica. O fotosensibilizador utilizado é o Photogem de origem russa, cujo custo é inferior ao produto americano, Photofrin, e com a mesma eficiência. O procedimento está sendo utilizado rotineiramente e com grande sucesso em pacientes humanos com carcinoma, atendidos na Fundação do Hospital Amaral Carvalho, localizado na cidade de Jaú, e no Hospital das Clínicas da Faculdade de Medicina de Ribeirão Preto. O Dr. Vanderlei Bagnato também está incentivando o uso do equipamento na medicina veterinária brasileira (Figura 2b). Como nos relatos clínicos, em medicina veterinária há grande variação com relação à fonte de luz e ao fotossensibilizador, são ainda necessários estudos clínicos para a comprovação da efetividade do método.

PEASTON et al. (1993) utilizaram a terapia fotodinâmica em 18 gatos com carcinoma de células escamosas, sendo três na aurícula e 16 na superfície externa do nariz. O fotossensibilizador foi o tetrasulfonato fitalocianina de alumínio e o laser a fonte de luz. Com um tratamento, houve êxito em 10 tumores. Dois tumores necessitaram de um ou dois tratamentos adicionais, cinco tumores tiveram resposta parcial e a resposta de dois não pôde ser avaliada. O procedimento foi bem tolerado pelos animais, que foram mantidos sem contato com a luz solar por duas semanas. Em seguida à aplicação, foi notado eritema nasal e edema facial, porém desapareceram num período de três a cinco dias. O tumor tornou-se necrótico e formou uma crosta sobre sua superfície. Esta se desprendeu entre duas e seis semanas após a terapia, deixando um leito de granulação que reepitelizou.

Reações adversas à terapia fotodinâmica com tetrasulfonato de fitalocianina foram citadas, por LEACH \& PEASTON (1994), após estudo com 45 gatos que apresentavam carcinoma de células escamosas localizados na aurícula ou no nariz externo e em 18 gatos hígidos utilizados apenas para estudo farmacocinético. Entre as reações foram citadas a necrose hepática, a colestase e a coagulação intravascular disseminada.

HAHN et al. (1998) empregaram a terapia fotodinâmica e tetrasulfonato de fitalocianina em dez gatos com diagnóstico histológico de carcinoma de células escamosas localizadas na cabeça, pálpebra e/ ou aurícula. Os autores verificaram remissão mais curta
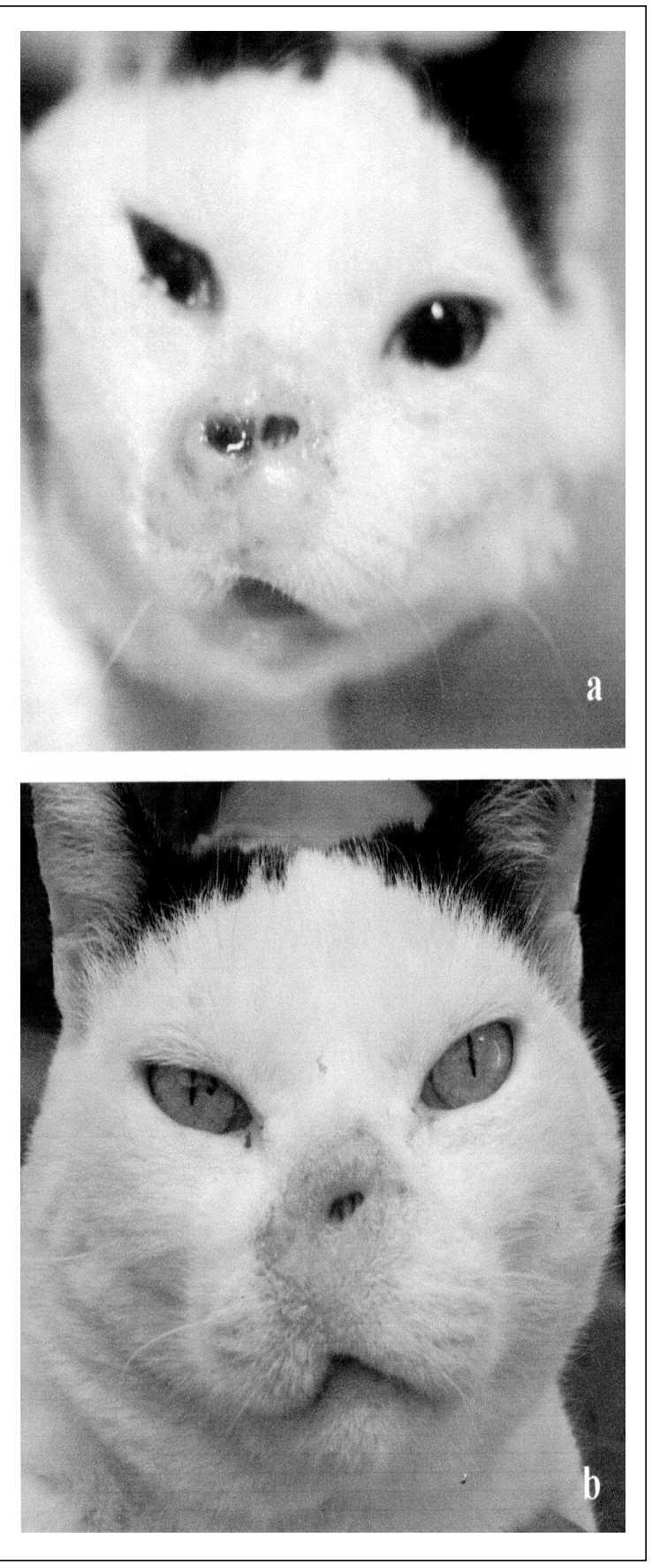

Figura 2 - Evolução de tratamentos utilizados em um gato com carcinoma de células escamosas localizado desde o dorso do nariz externo até o plano nasal. (a) Recidiva após prévia nosectomia e cinco meses da quimioterapia com doxorubicina e bleomicina. (b) Última avaliação realizada após um ano e cinco meses da terapia fotodinâmica, que mostra ausência de lesão. Foram efetuadas duas aplicações, em intervalo de 45 dias, com fotossensibilizador derivado da hematoporfirina e LED como fonte de luz. 
de tumores que receberam dose de luz $100 \mathrm{~J} / \mathrm{cm}^{2}$ (69 dias) do que os tratados com $200 \mathrm{~J} \mathrm{~cm}^{-2}$ (522 dias).

Um fotossensibilizador HPPH-23 foi usado na terapia fotodinâmica com laser de argônio, por MAGNE et al. (1997), em gatos com carcinoma de células escamosas localizados na face. Completa remissão da lesão foi detectada em tumores com menos de 1,5cm de diâmetro e não-invasivos; $56 \%$ de resposta ocorreu nos tumores com menos de 1,5cm de diâmetro e invasivos; e 18\% de resposta nos tumores com mais de $1,5 \mathrm{~cm}$ e invasivos. Os autores concluíram que o produto foi seguro e efetivo no tratamento de lesões precoces, mas foi detectada toxicidade com neoplasmas maiores.

Seis felinos com carcinoma de células escamosas localizados na face foram tratados por FRIMBERGER et al. (1998) com o fotossensibilizador benzofenotiazino. Ocorreu resposta parcial em dois animais e completa a longo prazo em quatro. Como efeitos colaterais foram detectados, náusea associada à injeção do medicamento $(n=1)$, a elevação de temperatura $(n=1)$, a inapetência $(n=1)$ e a neuropatia periférica transitória $(\mathrm{n}=1)$. Todos os pacientes foram expostos à luz do dia com menos de cinco dias após o tratamento, sem manifestação de fotossensibilização residual.

A terapia fotodinâmica com Photofrin foi testada em gatos com carcinoma de células escamosas localizados na face, por CHANG et al. (1998). Após 48 horas da aplicação do fotossenbilizador, foi aplicado o laser de argônio. A taxa de controle local, avaliada por um período de um ano, foi de $62 \%$. Não foram observados sinais clínicos, hematológicos ou bioquímicos de toxicidade.

LUCROY et al. (1999) utilizaram quatro gatos adultos saudáveis e um gato com carcinoma cutâneo de células escamosas para determinar se as células felinas podem converter o ácido 5-aminolevulínico a protoporfirina IX in vivo e in vitro. Após a administração intravenosa do ácido 5-aminolevulínico em protoporfirina foi detectada em todos os tecidos examinados, com maior intensidade de fluorescência no epitélio e no carcinoma de células escamosas. Todos os gatos desenvolveram hepatotoxicose. Os autores citaram que o produto pode ser usado em gatos, mas que doses maiores que $100 \mathrm{mg} \mathrm{kg}^{-1}$ não são seguras.

Um total de 13 carcinomas de células escamosas localizados no plano nasal $(\mathrm{n}=10)$, aurícula $(\mathrm{n}=2)$ e pálpebra $(\mathrm{n}=1)$ de gatos foram tratados por STELL et al. (2001) com o ácido de 5-aminolevulínico em creme e com laser de diodo centrado em $635 \mathrm{~nm}$. A taxa de resposta para lesões recebendo única dose de terapia foi de $85 \%$; contudo, ocorreu recidiva em média de 21 semanas em sete das 11 lesões que haviam mostrado resposta completa.

\section{CONCLUSÃO}

Existem várias possibilidades de tratamento para o carcinoma de células escamosas em gatos e a escolha deve ser estabelecida de acordo com o estadiamento do tumor, estado geral do paciente, colaboração do proprietário e a disponibilidade de equipamentos e medicamentos. A precocidade no diagnóstico tem efeito fundamental no prognóstico. A prevenção é outro fator importante e proprietários de gatos susceptíveis ao processo devem ser instruídos a limitar ao máximo a exposição desses animais à luz solar.

\section{INFORME VERBAL}

BAGNATO, V. (Grupo de Óptica, Instituto de Física, USP, São Carlos). Comunicação pessoal, 2005.

\section{AGRADECIMENTOS}

Ao Conselho Nacional de Desenvolvimento Científico e Tecnológico (CNPq), pelo fornecimento da bolsa de iniciação científica (PIBIC) para Isabelle Ferreira.

\section{REFERÊNCIAS}

BUHLES, W.C.; THEILEN, G.H. Preliminary evaluation of bleomycin in feline and canine squamous cell carcinoma. Am $\mathbf{J}$ Vet Res, v.34, n.2, p.289-291, 1973.

BURROWS, A.K. et al. Skin neoplasms of cats in Perth. Aust Vet Pract, v.24, n.1, p.11-15, 1994.

CHANG, C.J. et al. Photodynamic therapy for facial squamous cell carcinoma in cats using Photofrin. Changgeng-Yi-XueZa-Zhi, v.21, n.1, p.13-19, 1998.

CLARKE, R.E. Cryosurgical treatment of feline cutaneous squamous cell carcinoma. Aust Vet Pract, v.21, n.3, p.148152, 1991.

COX, N.R. et al. Tumors of the nose and paranasal sinuses in cats: 32 cases with comparison to a national database (1977 through 1987). J Am Anim Hosp Assoc, v.26, p.219-222, 1991.

DANIELL, M.D.; HILL, J.S. A history of photodynamic therapy. Aust N Z J Surg, v.61, p.340-348, 1991.

DONNER, G.S. The role of surgery in the treatment of common tumors of the nose and mouth. Vet Med, v.87, n.10, p.993998, 1992.

DOUGHERTY, T.J. et al. Photodynamic therapy. J Natl Cancer Inst, v.90, p.889-905, 1998. 
DOUGHERTY, T.J. An update on photodynamic therapy applications. J Clin Laser Med Surg, v.20, n.1, p.3-7, 2002.

FIDEL, J.L. et al. Proton irradiation of feline nasal planum squamous cell carcinomas using an accelerated protocol. Vet Radiol Ultrasound, v.42, n.6, p.569-575, 2001.

FRIMBERGER, A.E. et al. Photodynamic therapy of naturally occurring tumors in animals using a novel benzophenothiazine photosensitizer. Clin Cancer Res, v.4, n.9, p. 2207-2218, 1998.

HAHN, K.A. et al. Photodynamic therapy response in cats with cutaneous squamous cell carcinoma as a function of fluence. Vet Dermatol, v.9, n.1, p.3-7, 1998.

HENDERSON, B.W.; DOUGHERTY, T.J. How does photodynamic therapy work?. Photochem Photobiol, v.55, n.1, p.145-157, 1992.

LEACH, M.W.; PEASTON, A.E. Adverse drug reactions attributable to aluminum phthalocyanine tetrasulphonate administration in domestic cats. Vet Pathol, v.31, n.2, p.283287, 1994.

LUCROY, M.D. et al. Photodynamic therapy in veterinary medicine: current status and implications for applications in human disease. J Clin Laser Med Surg, v.14, n.5, p.305310, 1996.

LUCROY, M.D. et al. Preclinical study in cats of the prophotosensitizer 5-aminolevulinic acid. Am J Vet Res, v.60 n.11, p.1364-1370, 1999.

MACHADO, A.E.H. Terapêutica fotodinâmica: princípios, potencial de aplicação e perspectivas. Quím Nova, v.23, n.2, p.237-243, 2000.

MAGNE, M.L. et al. Photodynamic therapy of facial squamous cell carcinoma in cats using a new photosensitizer. Laser Surg Med, v.20, n.2, p.202-209, 1997.
MERKEL, L.K.; BIEL, M.A.C. Photodynamic therapy. In: WITHROW, S.J.; MacEWAN, E.G. Small animal clinical oncology. 3.ed. Philadelphia: Saunders, 2001. Chap.8, p.86-91.

MOORE, A.S.; OGILVIE, G.K. Skin tumors. In: OGILVIE, G.K.; MOORE, A.S. Feline oncology. USA: Veterinary Learning Systems, 2001. Chap.50, p.398-428.

PEASTON, A.E. et al. Photodynamic therapy for nasal and aural squamous cell carcinoma in cats. J Am Vet Med Assoc, v.202, n.8, p.1261-1265, 1993.

ROGERS, K.S. Feline cutaneous squamous cell carcinoma. Feline Pract, v.22, n.5, p.7-9, 1994.

RUSLANDER, D. et al. Cutaneous squamous cell carcinoma in cats. Compend Contin Educ Pract Vet, v.19, n.10, p.11191129, 1997

STRAW, R.C. Resection of the nasal planum. In: BOJRAB, M.J. et al. Current techniques in small animal surgery. 4.ed. Baltimore: Williams \& Wilkins, 1998. Chap.20, p. 343346 .

STELL, A.J. et al. Photodynamic therapy of feline superficial squamous cell carcinoma using topical 5-aminolaevulinic acid. J Small Anim Pract, v.42, n.4, p.164-169, 2001

THÉON, A.P. et al. Prognostic factors associated with radiotherapy of squamous cell carcinoma of the nasal plane in cats. J Am Vet Med Assoc, v.206, n.7, p.991-996, 1995.

THÉON, A.P. et al. Intratumoral administration of carboplatin for treatment of squamous cell carcinomas of the nasal plane in cats. Am J Vet Res, v.57, n.2, p.205-210, 1996.

THOMAS, R.C.; FOX, L.E. Tumors of the skin and subcutis. In: MORRISON, W.B. Cancer in dogs and cats. 2.ed. Jackson: Teton NewMedia, 2002. Chap.32, p.469-488.

WITHROW, S.J.; STRAW, R.C. Resection of the nasal planum in nine cats. J Am Anim Hosp Assoc, v.26, p.219-222, 1990. 